\title{
Venous thromboembolism - importance of national registries
}

\section{Marijan Bosevski* \\ University Cardiology Clinic,} Skopje, Macedonia

\author{
KEYWORDS: venous thromboembolism, registry.
}

CITATION: Cardiol Croat. 2014;9(9-10):415.

*ADDRESS FOR CORRESPONDENCE: University Cardiology Clinic, Vodnjanska bb, 1000 Skopje, Macedonia. / Phone: +38971238843 / E-mail: marijanbosevski@yahoo.com

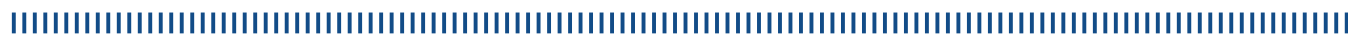

BACKGROUND: There is a debate regarding importance of national registries vs. multinational ones. A comparison of national vs. international registry on the venous thromboembolism (VT = deep venous thrombosis and/or pulmonary embolism) was done in this paper.

METHODS: 19 multinational registries and 5 national ones were found searching Clinical trials and PubMed/Medline Macedonian registry of VT (2013/14 done), is linked to Macedonian Society of Cardiology' web. Risk factors for VT, modality and duration of treatment and clinical outcome of these patients (pts) have been assessed in our National registry.

RESULTS: Most of the registries are dealing with short term prognosis of these pts. Important difference of our national registry is follow up for at least 1 year. All of registries are dealing with same drugs and clinical entry data set for risk factors. Some data for registries are suboptimal for evaluating VT, as surgical complication. The advantage of national registry is including pts nationwide, but not from academic centers only.

CONCLUSION: These observations have implications for performing a national registry on venous thromboembolism.
RECEIVED:

September 21, 2014

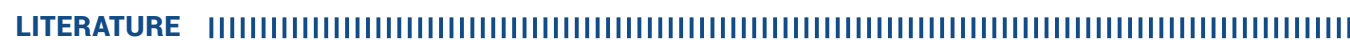

1. Lozano F, Trujillo-Santos J, Barrón M, et al; RIETE Investigators. Home versus in-hospital treatment of outpatients with acute deep venous thrombosis of the lower limbs. J Vasc Surg. 2014;59(5):1362-7.

2. Lopes LC, Eikelboom J, Spencer FA, et al. Shorter or longer anticoagulation to prevent recurrent venous thromboembolism: systematic review and meta-analysis. BMJ Open. 2014 Jul 4;4(7):e005674. 